\title{
Current trends of 24-h urinary iodine excretion in German schoolchildren and the importance of iodised salt in processed foods
}

\author{
Simone A. Johner ${ }^{1 *}$, Anke L. B. Günther ${ }^{2}$ and Thomas Remer ${ }^{1}$ \\ ${ }^{1}$ Research Institute of Child Nutrition, Rheinische Friedrich-Wilhelms-Universität Bonn, Heinstück 11, D-44225 Dortmund, \\ Germany \\ ${ }^{2}$ Department of Nutrition, Food and Consumer Sciences, Fulda University of Applied Sciences, Marquardstraße 35, D-36039 \\ Fulda, Germany \\ (Received 7 March 2011 - Revised 16 August 2011 - Accepted 20 August 2011 - First published online 11 October 2011)
}

\section{Abstract}

Worldwide, the iodisation of salt has clearly improved iodine status. In industrialised countries, iodised salt added to processed food contributes most to iodine supply. Yet it is unclear as to what extent changes in the latter may affect the iodine status of populations. Between 2004 and 2009, 24-h urinary iodine excretions (UIE) were repeatedly measured in 278 German children (6 to 12 years old) of the Dortmund Nutritional and Anthropometric Longitudinally Designed Study ( $n$ 707). Na excretion measurements and simultaneously collected 3-d weighed dietary records provided data on intakes of the most important dietary sources of iodine in the children's diet. Actual trends of UIE (2004-9) and contributions of relevant food groups were analysed by mixed linear regression models. Longitudinal regression analysis showed a plateau of UIE in 2004-6; afterwards, UIE significantly decreased till 2009 ( $P=0.01$; median 24-h UIE in 2004-6: 85.6 $\mu \mathrm{g} / \mathrm{d}$; 2009: $80 \cdot 4 \mu \mathrm{g} / \mathrm{d})$. Median urinary iodine concentration fell below the WHO criteria for iodine sufficiency of $100 \mu \mathrm{g} / 1 \mathrm{in} 2007-9$. Salt, milk, fish and egg intake $(\mathrm{g} / \mathrm{d})$ were significant predictors of UIE $(P<0.005)$; and the main sources of iodine were salt and milk ( 48 and $38 \%$, respectively). The present data hint at a beginning deterioration in the iodine status of German schoolchildren. A decreased use of iodised salt in industrially produced foods may be one possible reason for this development. Because of the generally known risks for cognitive impairment due to even mild iodine deficits in children, a more widespread use of iodised salt, especially in industrially processed foods, has to be promoted.

\section{Key words: Iodine status: Trend analysis: Healthy children: Iodised salt}

Worldwide, the most effective strategy to control iodine deficiency is universal salt iodisation ${ }^{(1,2)}$. In industrialised countries, where the main proportion of salt (about $80 \%$ ) is consumed through processed foods ${ }^{(3)}$, the use of iodised salt particularly in the food industry and food trade (e.g. bakeries, butchers) should be an important prophylactic measure to combat iodine deficiency. The impact of the latter can be assessed by urinary iodine measurements, a suitable method to monitor iodine status in large cohorts ${ }^{(4,5)}$. In Germany, for example, one of the first steps towards effective iodine deficiency prophylaxis was taken in 1989 by permitting the addition of iodised salt to industrially processed foods. In 1993, the repeal of legislative restrictions (i.e. allowing separate labelling of foods containing iodised salt) followed and markedly helped to improve the iodine status of the German population $^{(6,7)}$. Concomitant measurements of urinary iodine concentrations in children and adolescents allowed direct monitoring of the efficiency of these prophylaxis measures: until 1992, median urinary iodine concentration in 24-h urine samples was lower than $70 \mu \mathrm{g} / \mathrm{l}$; since 1993, it had been increasing steadily (to $95 \mu \mathrm{g} / 1$ until $1997^{(6)}$, and up to $117 \mu \mathrm{g} / \mathrm{l}$ until $\left.2003^{(8)}\right)$. The German Health Interview and Examination Survey for Children and Adolescents (KiGGS) during 2003-6 affirmed this positive development of iodine status by a measured median urinary iodine concentration of $117 \mu \mathrm{g} / \mathrm{l}$ in $0-17$-year-olds ${ }^{(9)}$. Despite the fact that this median urinary iodine concentration was above the WHO cut-off mark for iodine sufficiency of $100 \mu \mathrm{g} / \mathrm{l}$, it exceeded the cut-off level only by a narrow margin, suggesting that some fringe areas or population subgroups still may be at risk of inadequate iodine intakes. Especially in children, this picture is not satisfactory, as even mild iodine deficiency increases the risk of cognitive impairment ${ }^{(10-12)}$.

Abbreviations: DONALD, Dortmund Nutritional and Anthropometric Longitudinally Designed; EAR, Estimated Average Requirement; UIE, urinary iodine excretions.

*Corresponding author: S. A. Johner, fax + 49231 711581, email johner@fke-do.de 
In the coming years, according to scheduled public health measures in the European community and worldwide ${ }^{(13-16)}$, a general reduction of salt intake is expected. Therefore, the proportion of iodine intake that is provided by iodised salt will also decrease. To date, only one study evaluated the association between salt restriction and iodine deficiency in adults and provided a first hint that in persons who are consuming low levels of iodine, salt restriction may cause iodine deficiency ${ }^{(17)}$.

In Germany, actual observations already show a slow but constant decrease in the use of iodised salt in processed foods since $2004^{(7,18)}$. We intended to investigate whether this development has already affected the iodine status of German schoolchildren, to depict possible consequences of a general salt reduction (and therefore also iodine reduction) in processed foods. For this purpose, we studied 24-h urinary iodine excretion (UIE) of 6-12-year-old children from 2004 to 2009, to monitor the current development of iodine status of children in Germany. Concomitant investigations of the children's intakes of the most important dietary iodine sources (e.g. iodised salt, milk, fish) provided the basis to calculate the contributions of the latter to iodine excretion and to study related changes over time; with special regard to salt intake.

\section{Methods}

\section{Subjects and study design}

The present investigation was carried out in healthy children selected from the ongoing Dortmund Nutritional and Anthropometric Longitudinally Designed (DONALD) Study, an open cohort study, since 1985 gathering information about diet, development and metabolism between infancy and adulthood in healthy participants ${ }^{(8,19)}$. The children visit the Research Institute of Child Nutrition, Dortmund, once a year for examinations and assessments. The assessments include 3-d weighed dietary records, anthropometric measurements, collection of 24-h urine samples, and interviews on lifestyle and medical assessments. The DONALD Study is exclusively observational and non-invasive (until the age of 18 years). The study was conducted according to the guidelines laid down in the Declaration of Helsinki and was approved by the Ethics Committee of the University of Bonn (Germany). All examinations are performed with parental, and later on with the children's written consent.

For the present evaluation, all children who had $\geq 1$ completely collected 24-h urine sample along with a 3-d weighed dietary record (encompassing the day of urine collection) during 2004-9 at the age of 6-12 years were enrolled. Only those examinations performed at ages 6-12 were included for each child. Exclusion criterion for an incompletely collected urine sample was a body weight-related 24-h-creatinine excretion rate $<0.1 \mathrm{mmol} / \mathrm{kg}$ per $\mathrm{d}^{(19)}$. A total of 287 children met the criteria, providing 723 urine samples and corresponding dietary records. In order to obtain a preferably homogeneous study sample, urine samples and corresponding dietary records were excluded in case of no or irregular use of iodised table salt, iodine-containing drug use, or intake of iodine-containing supplements during the time of the respective urine collection. This was true for sixteen observations of fifteen children. As for six children, further repeated observations were available, and only nine children had to be completely excluded from the study sample. Therefore, 278 children with 707 repeatedly collected 24-h urine samples and related dietary records remained for the present investigations. Overall, 188 children (68\%) had at least two out of a maximum of six possible measures during the 5-year period.

\section{Dietary records}

To estimate the individual food and nutrient intake, 3-d weighed dietary records were used. On three consecutive days, the weight of all foods and beverages consumed was recorded using a digital, regularly calibrated food scale to the nearest $1 \mathrm{~g}$. Out-of-home consumed food was estimated by semi-quantitative recording (e.g. numbers of glasses, cups). Intakes of energy, nutrients (including food fortification and nutritional supplements) and food groups were calculated as individual means of the three recorded days by using our in-house nutrient database $\operatorname{LEBTAB}^{(20)}$, which contains detailed data on the energy and nutrient content of all recorded food items and is continuously updated. The following food groups were relevant for the present analysis: milk and whey-based milk products, salt-water fish, eggs and egg products, and meat and meat products. Because salt intake could not be quantitatively recorded in the dietary records, it was estimated from 24-h urinary Na measurements $(\mathrm{g} / \mathrm{d})$.

\section{Urine collection and urinary measurements}

The urine collection of the DONALD participants was generally carried out on the third day of the 3-d weighed dietary records. The procedures for the $24-\mathrm{h}$ urine collections have been described in detail previously ${ }^{(8)}$.

Iodine concentration was determined in the 24-h urine samples by a modified Sandell-Kolthoff method after acidic wet-ashing of the samples ${ }^{(21)}$; and 24-h $\mathrm{Na}$ excretion was measured by flame atomic absorption spectrometry with a Perkin Elmer 1100 Spectrometer (Perkin Elmer, Überlingen, Germany). For determining completeness of the urine collection, creatinine concentration was quantified in all samples by the Jaffé method with the use of a creatinine analyser (Beckman-2; Beckman Instruments, Inc., Fullerton, CA, USA).

\section{Anthropometric measurements}

Anthropometric measurements of the DONALD participants were performed at each annual visit by nurses who had been trained according to standard procedures ${ }^{(22)}$, with the children dressed in underwear only and barefoot. Standing height was measured with a stadiometer (Harpenden, Crymych, UK) to the nearest $0 \cdot 1 \mathrm{~cm}$, and weight was measured on an electronic scale (Seca 753E; Seca Weighing and Measuring System, Hamburg, Germany) to the nearest $0 \cdot 1 \mathrm{~kg}$. From these measurements, BMI and body surface area were calculated, the latter according to the formula of Du Bois \& Du 
Bois $^{(23)}$. Sex- and age-independent BMI-standard deviation scores were calculated by using the German national reference data ${ }^{(24)}$.

\section{Statistical analysis}

All calculations were performed with SAS procedures (version 9.1.3, SAS Institute, Cary, NC, USA). Significance was defined as $P<0.05$.

Anthropometric, dietary and urinary characteristics are presented sex-stratified as well as stratified by time period (2004-6 v. 2007-9), given as means and standard deviations or medians with interquartile ranges when appropriate. Sex differences were evaluated by unpaired $t$ test or Wilcoxon rank sum test, differences between the two time periods were tested by a linear mixed-effects regression model (PROC MIXED in SAS, adjusted for sex and age) to account for the dependency between repeated measurements on the same child. A random statement accounted for variation between the individuals; the structure of the variance covariance matrix was set to compound symmetry.

Linear mixed-effects regression models (PROC MIXED) were also used to analyse time trends in iodine excretion (2004-9). In contrast to other models, e.g. linear regression for balanced longitudinal data (PROC GLM in SAS), the mixed linear regression model considers all available measurements rather than using only participants with complete follow-up data ${ }^{(25)}$. A random statement was included to allow for variation between the individuals, with the variance covariance structure set to compound symmetry. Since no interaction between sex and the relationship of UIE to time was observed, data from girls and boys were pooled.

The basic model included the predictor variable time (continuously in years since 2004), sex, age and urine volume ${ }^{(26)}$. Furthermore, we added creatinine excretion (standardised to a body surface area of $1.73 \mathrm{~m}^{2}$ ) to account for correlated measurement errors potentially introduced by the fact that iodine excretion and urine volume were measured in the same urine sample ${ }^{(27)}$.

Subsequently, the dietary iodine sources, such as salt intake (estimated by Na excretion), milk, fish, egg and meat intake $(\mathrm{g} / \mathrm{d})$, were included as further fixed effects in a second model. Energy intake level, BMI-standard deviation scores and season were considered as potential confounders but were not included since none of them considerably modified the effect of time on iodine excretion or significantly predicted the outcome variable or improved the fit of the model (Akaike's information criterion). Finally, analyses were repeated time-stratified (2004-6v. 2007-9) to address potential changes of the contributions of the different dietary iodine sources to iodine excretion over time.

\section{Results}

In Tables 1 and 2, anthropometric, dietary and urinary characteristics of the study sample are presented. UIE $(\mu \mathrm{g} / \mathrm{d})$ and concentration $(\mu \mathrm{g} / \mathrm{l})$ were significantly lower in girls than in boys $(P<0 \cdot 0005)$. However, when corrected for individual energy intake (which was higher in boys), statistical differences disappeared $(P=0 \cdot 13)$. Urinary iodine concentration significantly decreased from $2004-6$ to 2007-9 $(P<0.0005)$ and fell below the WHO recommendation of $100 \mu \mathrm{g} / 1$ in the second time period (2007-9).

Longitudinal trend analysis (i.e. the basic linear mixedeffects regression model adjusted for sex, age, urine volume and creatinine) of 24-h UIE showed a trend of a decline over the 6-year period under study (2004-9; $\beta=-1.05$, $P=0.08)$. When this analysis was stratified by time (2004-6 v. 2007-9), a significant decline of urinary iodine was only observable in the second time interval (2007-9; $\beta=-3 \cdot 86$, $P=0 \cdot 01$ ); whereas from 2004 to 2006 , UIE remained constant $(\beta=0.92, P=0.58$; Fig. 1$)$. In Fig. 1 , this trend is visualised by presenting the median daily UIE/year (2004-9). To obtain an adapted reference value for 24-h UIE that reflects an adequate iodine intake, we corrected the recommended dietary iodine intakes for an average portion of $15 \%$ of non-urinary iodine losses (i.e. intake recommendation $\times 0 \cdot 85$ ). Compared to the estimated average requirement (EAR) of iodine set by the Institute of Medicine $(65 \mu \mathrm{g} / \mathrm{d}$ for $4-8$-year-olds, $73 \mu \mathrm{g} / \mathrm{d}$ for 9-13-year-olds ${ }^{(28)}$, translating to UIE of 55 and $62 \mu \mathrm{g} / \mathrm{d}$, respectively), $12.75 \%$ of the children had an iodine intake below the EAR in 2004-6; this proportion increased to $15.5 \%$ in 2007-9. When using the RDA as reference $(90 \mu \mathrm{g}$ $\mathrm{d}$ for 4-8-year-olds, $120 \mu \mathrm{g} / \mathrm{d}$ for 9-13-year-olds ${ }^{(28)}$, translating to UIE of 77 and $102 \mu \mathrm{g} / \mathrm{d}$, respectively), $51.0 \%$ of the population in the first time period and $57.2 \%$ in the second time period did not reach the reference.

In a second longitudinal regression model, the dietary iodine sources of milk, fish, meat and egg intake, and $\mathrm{Na}$ excretion as a marker of salt intake were included (Table 3). All were significant predictors of UIE $(P<0.05)$, except meat intake in the second time period (2007-9: $P=0.58)$. The contributions of $\mathrm{Na}$ excretion and fish intake to UIE decreased substantially from the first to the second time period (time-stratified models), as indicated by lower regression coefficients. However, inclusion of Na-by-time or fish-by-time interactions in the basic longitudinal regression model could not confirm significance for these changes $(\mathrm{Na} \times$ time, $P=0 \cdot 3$, fish $\times$ time, $P=0 \cdot 2$; here, time was treated as categorical variable, categories: 2004-6 and 2007-9).

The quantitatively most important iodine sources in the children's diet were salt and milk (salt: 48\%, milk: 38\%; Fig. 2).

\section{Discussion}

In the last decades, the German population has experienced a clear improvement in their iodine status, indicated by constantly increasing 24 -h UIE rates ${ }^{(8,9,29-31)}$. The present analysis of UIE trends in children from 2004 to 2009, however, suggests that this former increase did not continue after 2003. From 2007 onwards, it has rather reversed into a decline. In 2009 , median UIE/d was about $5 \cdot 1 \mu \mathrm{g}(6 \%)$ lower than in the plateau phase 2004-6. The parallel investigation of the children's dietary intakes suggested a decreased use of iodised salt as a proportion of total salt in processed foods to be one possible reason for the decreasing of UIE. 
Table 1. Study sample characteristics at the time of first 24-h urine collection within 2004-9 of $n 278$ participants (6 to 12 year olds) of the Dortmund Nutritional and Anthropometric Longitudinally Designed Study, stratified by sex (Mean values and standard deviations; median values and 25th (P25) and 75th (P75) percentiles)

\begin{tabular}{|c|c|c|c|c|c|}
\hline & \multicolumn{2}{|c|}{ Boys ( $n$ 144) } & \multicolumn{2}{|c|}{ Girls ( $n$ 134) } & \multirow[b]{2}{*}{$P^{*}$} \\
\hline & Mean & SD & Mean & SD & \\
\hline Age (years) & 7.85 & 2.03 & $8 \cdot 10$ & $2 \cdot 14$ & 0.5 \\
\hline \multicolumn{6}{|l|}{ Anthropometrics } \\
\hline Weight (kg) & $29 \cdot 34$ & 9.03 & 28.73 & 8.63 & 0.6 \\
\hline Height (cm) & 131.66 & $12 \cdot 84$ & $131 \cdot 16$ & $13 \cdot 29$ & 0.7 \\
\hline BMI $\left(\mathrm{kg} / \mathrm{m}^{2}\right)$ & $16 \cdot 56$ & $2 \cdot 28$ & $16 \cdot 32$ & 2.07 & 0.3 \\
\hline \multirow[t]{2}{*}{ BMI-SDS } & 0.08 & 0.94 & -0.06 & 0.86 & 0.3 \\
\hline & Median & P25-P75 & Median & P25-P75 & \\
\hline \multicolumn{6}{|l|}{ Dietary parameters } \\
\hline Energy intake (MJ/d) & $6 \cdot 8$ & $6 \cdot 0-8 \cdot 1$ & $6 \cdot 2$ & $5 \cdot 5-7 \cdot 2$ & 0.0004 \\
\hline \multicolumn{6}{|l|}{ Dietary intakes (g/d) } \\
\hline Milk† & $260 \cdot 6$ & $151 \cdot 5-377 \cdot 1$ & $227 \cdot 6$ & $127 \cdot 2-335 \cdot 2$ & 0.07 \\
\hline Fish $\ddagger$ & 0.0 & $0.0-11.4$ & 0.0 & $0-12 \cdot 1$ & 0.5 \\
\hline Eggs§ & 4.4 & $0.0-19.5$ & $10 \cdot 4$ & $1 \cdot 2-22 \cdot 7$ & 0.09 \\
\hline Meat $\|$ & $62 \cdot 3$ & $38 \cdot 2-94 \cdot 2$ & $59 \cdot 7$ & $36 \cdot 3-81 \cdot 8$ & 0.5 \\
\hline \multicolumn{6}{|l|}{ Dietary intakes (g/MJ per d) } \\
\hline Milk† & $36 \cdot 9$ & $23 \cdot 2-53 \cdot 2$ & $35 \cdot 9$ & $20 \cdot 6-49 \cdot 6$ & 0.5 \\
\hline Fish $\ddagger$ & 0.0 & $0.0-1.6$ & 0.0 & $0 \cdot 0-2 \cdot 1$ & 0.4 \\
\hline Eggs§ & 0.6 & $0 \cdot 0-3 \cdot 2$ & 1.7 & $0 \cdot 2-3 \cdot 6$ & 0.05 \\
\hline Meat $\|$ & $9 \cdot 1$ & $5 \cdot 5-13 \cdot 0$ & 9.5 & $6 \cdot 1-12 \cdot 6$ & 0.6 \\
\hline \multicolumn{6}{|l|}{ Urinary parameters } \\
\hline Urine volume (litres/d) & 0.72 & $0.53-0.92$ & 0.75 & $0.54-1.04$ & 0.2 \\
\hline Iodine excretion $(\mu \mathrm{g} / \mathrm{d})$ & $86 \cdot 3$ & $68 \cdot 6-111 \cdot 8$ & $73 \cdot 6$ & $58 \cdot 6-94.9$ & 0.0003 \\
\hline lodine excretion ( $\mu \mathrm{g} / \mathrm{MJ}$ per $\mathrm{d})$ & $12 \cdot 4$ & $10 \cdot 3-16 \cdot 1$ & $11 \cdot 4$ & $9 \cdot 7-15 \cdot 3$ & $0 \cdot 13$ \\
\hline Iodine concentration $(\mu \mathrm{g} / \mathrm{l})$ & $121 \cdot 3$ & $98 \cdot 7-159 \cdot 1$ & $97 \cdot 7$ & $72 \cdot 8-134 \cdot 1$ & $<0.0001$ \\
\hline Na excretion $(\mathrm{g} / \mathrm{d})$ & 1.8 & $1 \cdot 4-2 \cdot 2$ & 1.7 & $1 \cdot 3-2 \cdot 2$ & 0.11 \\
\hline Na excretion (g/MJ per d) & 0.3 & $0.2-0.3$ & 0.3 & $0.2-0.3$ & 0.6 \\
\hline
\end{tabular}

SDS, standard deviation score.

* Sex differences were tested with an unpaired $t$ test or Wilcoxon rank sum test, respectively. † Only whey-based milk products.

$\ddagger$ Only salt-water fish products.

$\S$ Eggs and egg products.

II Meat and meat products.

The WHO recommendation of a median urinary iodine concentration of $>100 \mu \mathrm{g} / 1$ in a population ${ }^{(3)}$ was not achieved after 2007 (for data, see legend of Fig. 1). As this reference marker can substantially be confounded by the hydration status of the population investigated ${ }^{(8)}$, we compared the children's absolute 24-h UIE rates $(\mu \mathrm{g} / \mathrm{d}$ ) (that nearly reflect total daily iodine intakes ${ }^{(32)}$ ) with the recommended dietary iodine intakes (Fig. 1). Depending on the selected reference value, the classification of iodine nutritional status of the children differed markedly. When compared to the $\mathrm{RDA}^{(28)}$, the average daily nutrient intake that is estimated to meet the needs of $97.5 \%$ of the healthy population, more than $50 \%$ of the children did not reach the reference value. When applying the $\mathrm{EAR}^{(28)}$, which is estimated to meet the requirements of half of the healthy individuals in a group, only about $15 \%$ of the children can be categorised to have an inadequate iodine intake. As stated by the Institute of Medicine, the RDA - in contrast to the EAR - is an inappropriate approach to assess the proportion of nutrient inadequacy in a group ${ }^{(33)}$. It leads to an overestimation of the true prevalence, given that, by definition, the RDA is the intake level that exceeds the requirement of a large proportion of individuals in the group ${ }^{(33)}$. Especially, when drawing public health conclusions, it is important to consider the meaning and interpretation of the different reference values for the decision on which value is the most appropriate. According to our data, using the EAR as reference, only a moderate proportion of the examined children (about 15\%) are at risk of dietary iodine inadequacy. However, of concern is that the proportion of the population below the EAR is increasing, thus lending strong evidence that the iodine supply in the German population is deteriorating.

To identify possible dietary reasons for the declining iodine excretion rates, we studied the development of the respective regression coefficients (i.e. $\beta$ of Na excretion, milk, fish, egg and meat intake) over the two time periods investigated (2004-6 v. 2007-9; Table 3). A decrease in the second time period existed for $\mathrm{Na}$ excretion and for fish intake; although these changes did not reach statistical significance. Regression coefficients describe the expected change of the outcome variable (here: UIE) for a one-unit increase in the respective covariate (here: $\mathrm{Na}$ excretion and food groups). Consequently, they directly reflect the iodine content of the investigated food groups. With respect to $\mathrm{Na}$ excretion, a decreased $\beta$-value indicates a decreased proportion of iodised salt consumed among total salt consumed. Iodine intake from iodised salt at the household level is very stable (the proportion of households using iodised salt was $79 \%$ in 2004, and about $80 \%$ in $2009^{(34)}$, mandatory iodine content ranging from 15 
Table 2. Anthropometric, dietary and urinary parameters, stratified by time period (total measurements $n 707$ of 278 children (6 to 12 years old) participating in the Dortmund Nutritional and Anthropometric Longitudinally Designed Study)

(Mean values and standard deviations; median values and 25th (P25) and 75th (P75) percentiles)

\begin{tabular}{|c|c|c|c|c|c|}
\hline & \multicolumn{2}{|c|}{$2004-6$ (n 345) } & \multicolumn{2}{|c|}{$2007-9$ (n 362) } & \multirow[b]{2}{*}{$P^{\star}$} \\
\hline & Mean & SD & Mean & SD & \\
\hline Age (years) & $9 \cdot 0$ & $2 \cdot 0$ & 8.9 & $2 \cdot 0$ & 0.6 \\
\hline \multicolumn{6}{|l|}{ Anthropometrics } \\
\hline Weight (kg) & $32 \cdot 9$ & $9 \cdot 4$ & 32.5 & $9 \cdot 6$ & 0.4 \\
\hline Height $(\mathrm{cm})$ & $137 \cdot 6$ & $12 \cdot 6$ & $137 \cdot 1$ & $13 \cdot 2$ & 0.8 \\
\hline $\mathrm{BMI}\left(\mathrm{kg} / \mathrm{m}^{2}\right)$ & $17 \cdot 0$ & 2.5 & $16 \cdot 9$ & $2 \cdot 4$ & 0.6 \\
\hline \multirow[t]{2}{*}{ BMI-SDS } & 0.07 & 0.94 & 0.03 & 0.88 & 0.6 \\
\hline & Median & P25-P75 & Median & P25-P75 & \\
\hline \multicolumn{6}{|l|}{ Dietary parameters } \\
\hline Energy intake (MJ/d) & $6 \cdot 85$ & $6 \cdot 02-7 \cdot 76$ & $6 \cdot 88$ & $6.00-7.89$ & 0.9 \\
\hline \multicolumn{6}{|l|}{ Dietary intakes (g/d) } \\
\hline Milk† & 242.93 & $145 \cdot 53-367 \cdot 10$ & $226 \cdot 59$ & $138 \cdot 43-349 \cdot 47$ & 0.5 \\
\hline Fish $\ddagger$ & 0.00 & $0.00-15 \cdot 53$ & 0.00 & $0.00-16 \cdot 00$ & 0.3 \\
\hline Eggs§ & $6 \cdot 77$ & $0.03-19 \cdot 27$ & 9.50 & $0.23-21.05$ & 0.3 \\
\hline Meat $\|^{\dagger}$ & $66 \cdot 26$ & $44 \cdot 42-91 \cdot 57$ & $60 \cdot 65$ & $38 \cdot 43-88 \cdot 13$ & $0 \cdot 1$ \\
\hline \multicolumn{6}{|l|}{ Dietary intakes (g/MJ per d) } \\
\hline Milk† & 36.06 & $21 \cdot 50-51 \cdot 38$ & $32 \cdot 32$ & $19 \cdot 92-52 \cdot 18$ & 0.4 \\
\hline Fish $\ddagger$ & 0.00 & $0.00-2 \cdot 18$ & 0.00 & $0.00-2 \cdot 32$ & 0.3 \\
\hline Eggs§ & 1.00 & $0.0-2.91$ & 1.41 & $0.03-3 \cdot 16$ & 0.4 \\
\hline Meat $\|^{\|}$ & $9 \cdot 75$ & $6 \cdot 16-13 \cdot 32$ & 8.75 & $5.63-13.02$ & 0.2 \\
\hline \multicolumn{6}{|l|}{ Urinary parameters } \\
\hline Urine volume (litres/d) & 0.77 & $0.56-1.06$ & 0.85 & $0.64-1.07$ & 0.6 \\
\hline lodine excretion $(\mu \mathrm{g} / \mathrm{d})$ & $85 \cdot 58$ & $68.44-113.45$ & 83.37 & $65 \cdot 00-109 \cdot 90$ & 0.2 \\
\hline lodine excretion ( $\mu \mathrm{g} / \mathrm{MJ}$ per $\mathrm{d})$ & $12 \cdot 90$ & $10 \cdot 39-16 \cdot 14$ & $12 \cdot 13$ & $9 \cdot 84-15 \cdot 01$ & 0.2 \\
\hline Iodine concentration $(\mu \mathrm{g} / \mathrm{l})$ & $110 \cdot 10$ & $81 \cdot 50-150 \cdot 20$ & 98.05 & $74 \cdot 90-132 \cdot 3$ & 0.0008 \\
\hline Na excretion (g/d) & 1.91 & $1.50-2.47$ & 1.99 & $1.51-2.54$ & 0.3 \\
\hline Na excretion (g/MJ per d) & 0.29 & $0.22-0.35$ & 0.29 & $0.22-0.37$ & 0.3 \\
\hline
\end{tabular}

SDS, standard deviation score.

*Differences between the two time periods were tested with a linear mixed-effects regression model (PROC MIXED in SAS) to account for the dependency between repeated measurements on the same child. Regression models were adjusted for sex and age (for the comparison of mean age, only adjustment for sex was conducted).

†Only whey-based milk products.

$\ddagger$ Only salt-water fish products.

$\S$ Eggs and egg products.

\| Meat and meat products.

to $25 \mu \mathrm{g} / \mathrm{g}$ salt in Germany $\left.{ }^{(35)}\right)$. Table salt amounts to only a small proportion of the total daily salt consumption, i.e. about $80 \%$ of the total salt intake stems from processed foods ${ }^{(3)}$. As we included only those children who regularly used iodised table salt at home, the observed decrease in the respective regression coefficient should be primarily attributable to changes in the use of iodised salt in processed foods. These results are in good agreement with actual statistics about the developments in the German salt industry: since 2004, the market shares pertaining to the use of iodised salt in industrial food production have decreased from $35 \%$ in $2004^{(7)}$ to $29 \%$ currently $^{(18,34)}$. Reasons for this may be lowprice imports of non-iodised salt and non-iodised processed foods, price differences for conventional and iodised salt, and until a few years ago trade barriers at the level of the European Union for food industry ${ }^{(34)}$. As salt is the main contributor to UIE (48\%; Fig. 2), our results suggest this development to be one possible reason for the declining UIE rates starting in 2007. However, because of the lack of statistical confirmation, these results should only be seen as a first hint that has to be verified by further analysis.
Besides a decreased use of iodised salt in the previous years, our analysis also indicates a lower iodine content of consumed fish (observable by a decreased regression coefficient of fish in the second time period) to be one possible reason for the decreasing UIE rates. This result is somewhat striking, as we could not find any changes in the consumed fish species in our children over time (data not shown; in both time periods the fish most consumed were coalfish, salmon and redfish). One possible explanation could be the worldwide rapid expansion of aquacultures for fish production $^{(36)}$, as first studies indicate a decreased iodine content of fish from aquaculture compared to wild fish ${ }^{(37)}$. However, due to the low fish consumption in Germany, its quantitative contribution to iodine supply is low compared to iodised salt (3\% v. 48\%, Fig. 2), and the observed decrease should not be very important for the development of iodine nutritional status.

The impact of milk on UIE remained constant over the investigated time period and was at a similar level as in 2000-3 (an ingestion of $100 \mathrm{~g}$ milk resulted in an iodine excretion of about $70^{(8)}$ and $80 \mu \mathrm{g}$ (Table 3), respectively). 


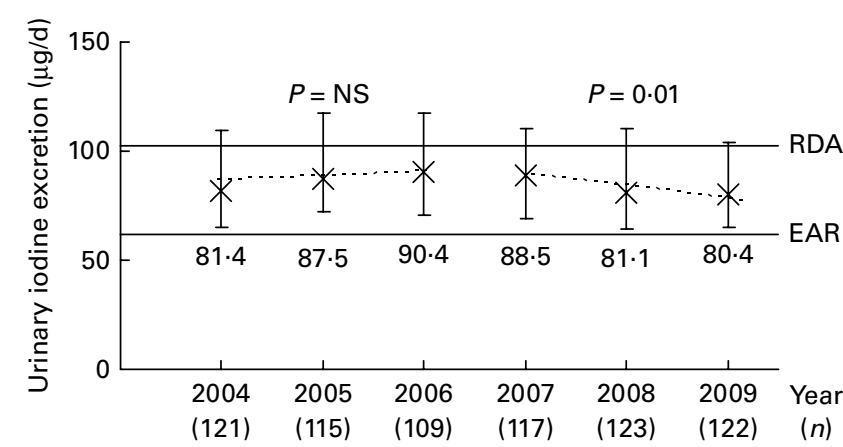

Fig. 1. Median $(x)$ and interquartile range $(I)$ of urinary $24-h$ iodine excretion in 6-12-year-old schoolchildren, participating in the Dortmund Nutritional and Anthropometric Longitudinally Designed Study, between 2004 and 2009. Dashed lines plot the predicted values based on the time-stratified longitudinal regression model adjusted for sex, age, urine volume and creatinine. For comparison, development of urinary iodine concentration $(\mu \mathrm{g} / \mathrm{l})$ : 2004: 113.1 (81.9-144.2) $\mu \mathrm{g} / \mathrm{l} ; 2005: 114.8$ (81.0-155.1) $\mu \mathrm{g} / \mathrm{l} ; 2006: 101.8$ (81.5-143.6) $\mu \mathrm{g} / \mathrm{l} ; \quad 2007$ : $101.2 \quad(81.5-139.3) \mu \mathrm{g} / \mathrm{l} ; \quad 2008: \quad 92.9$ (78.4120.3) $\mu \mathrm{g} / \mathrm{l}$; 2009: $96.9(72.7-127.1) \mu \mathrm{g} / \mathrm{l}$. RDA and estimated average requirement (EAR) were derived from the iodine intake recommendations of the Institute of Medicine (IoM) ${ }^{(28)}$ for 9 year olds (according to the mean age of the children, Table 2). The recommended iodine intakes were corrected for non-urinary iodine losses, assuming an average $15 \%$ loss through the faeces and sweat, to obtain the corresponding adapted 24-h urinary iodine excretion. This yielded the approximate excretion reference values of 102 (IoM RDA) and $62 \mu \mathrm{g}$ iodine/d (IoM EAR), respectively.

Therefore, the strong increase in the iodine content of milk from 1996 to 2003 did obviously not continue after 2003. Compared to other European countries, like the $\mathrm{UK}^{(38)}$, in Germany milk and milk products are of lower importance for iodine supply, because of the lower iodine concentrations (about $100-120 \mu \mathrm{g} / 1)^{(39,40)}$.

Apart from the characterisation of iodine status, the data of our investigation can also be used to estimate the current amounts of salt intake in children. $\mathrm{Na}$ is excreted almost quantitatively in the urine and 24-h urine collections are deemed to be the 'gold standard' for determining the daily $\mathrm{Na}$ and salt intake in a population ${ }^{(41,42)}$. According to the upper level for $\mathrm{Na}$ intake given by the US Food and Nutrition Board of $1.9 \mathrm{~g} / \mathrm{d}$ for $4-8$-year-olds and $2.2 \mathrm{~g} / \mathrm{d}$ for $9-13$-year-olds ${ }^{(43)}$, the observed median $\mathrm{Na}$ excretion in our population of $1.7-1.8 \mathrm{~g} / \mathrm{d}$ (which equals a total salt intake of about $4.5 \mathrm{~g} / \mathrm{d}$ ) indicates that nearly $50 \%$ of the children met this upper level and a substantial proportion even exceeded it. As our DONALD Study population in general shows a rather higher socio-economic status, compared to the German population $^{(44)}$, it can be assumed that the actual average amounts of salt intake in German children are somewhat higher. Against the background of possible programming effects of an inappropriate salt intake in childhood with respect to blood pressure elevations in later life ${ }^{(45)}$, these data indicate a need for future public health measures in children.

The strength of the present investigation is the availability of 24-h urine collections. It enabled us to assess the prevalence of children who are at risk of dietary iodine inadequacy more precisely than the use of the urinary iodine concentration of $100 \mu \mathrm{g} / \mathrm{l}$ as the reference median for a population. Also for the comparison of iodine status between subgroups, the use of 24-h UIE seems more suitable. Seeming sex differences in iodine status, indicated by significantly lower iodine concentrations in girls (Table 1), disappeared when relating 24-h UIE to energy intake. The sex differences in iodine concentration can be explained by the frequently more favourable beverage intake of German girls compared to boys ${ }^{(46)}$. The lower 24-h UIE in girls is physiologically based on their lower total food and energy intake on average, which can be accounted for by considering individual energy intake. Accordingly, the collection of 24-h urine samples allowed us to perform a much more sensitive and hydration statusindependent investigation of the children's iodine status.

A limitation of our study was that not all of the children had repeated collections of 24-h urine samples and dietary records. This, for example, impedes the estimation of customary salt intake from 24-h Na excretion. However, the calculated regression coefficients that estimate the contribution of salt intake to iodine supply and allowed thus to assess the proportion of iodised to total salt consumption (and not the amount consumed) should not be relevantly biased. A further

Table 3. Trend and predictors of 24-h urinary iodine excretion ( $\mu \mathrm{g} / \mathrm{d})$ in 278 children (6 to 12 years old) participating in the Dortmund Nutritional and Anthropometric Longitudinally Designed Study with urine samples collected repeatedly between 2004 and 2009 (707 urine samples in total)*

( $\beta$-Coefficients with their standard errors)

\begin{tabular}{|c|c|c|c|c|c|c|c|c|c|}
\hline \multirow[b]{3}{*}{ Predictors } & \multicolumn{9}{|c|}{ Urinary iodine excretion $(\mu \mathrm{g} / \mathrm{d})$} \\
\hline & \multicolumn{3}{|c|}{$\begin{array}{c}2004-9 \text { ( } n 707 \text { urine samples, } \\
278 \text { children) }\end{array}$} & \multicolumn{3}{|c|}{$\begin{array}{c}\text { 2004-6 ( } n 345 \text { urine samples, } \\
185 \text { children) }\end{array}$} & \multicolumn{3}{|c|}{$\begin{array}{c}\text { 2007-9 ( } n 362 \text { urine samples, } \\
199 \text { children) }\end{array}$} \\
\hline & $\beta$ & SE & $P$ & $\beta$ & SE & $P$ & $\beta$ & SE & $P$ \\
\hline Trend (years) & $-1 \cdot 10$ & 0.46 & 0.02 & 0.49 & 1.29 & 0.71 & $-2 \cdot 83$ & $1 \cdot 28$ & 0.03 \\
\hline Na excretion $(g / d)$ & $11 \cdot 76$ & 1.25 & $<0.0001$ & 13.06 & 1.86 & $<0.0001$ & 10.46 & 1.65 & $<0.0001$ \\
\hline Milk† (g/d) & 0.08 & 0.005 & $<0.0001$ & 0.08 & 0.007 & $<0.0001$ & 0.08 & 0.006 & $<0.0001$ \\
\hline Fish $\ddagger(g / d)$ & 0.35 & 0.06 & $<0.0001$ & 0.48 & 0.09 & $<0.0001$ & 0.25 & 0.08 & 0.002 \\
\hline Eggs§ (g/d) & 0.22 & 0.05 & $<0.0001$ & 0.22 & 0.08 & 0.007 & 0.27 & 0.08 & 0.001 \\
\hline Meat\|l $(g / d)$ & 0.04 & 0.02 & 0.04 & 0.08 & 0.03 & 0.02 & 0.02 & 0.03 & 0.58 \\
\hline
\end{tabular}

${ }^{\star}$ Results of the linear mixed-effects regression model (PROC MIXED in SAS); adjusted for sex, age, creatinine excretion (mmol/d) and urine volume (I/d). †Only whey-based milk products.

$\ddagger$ Only salt-water fish products.

$\S$ Eggs and egg products.

\| Meat and meat products. 


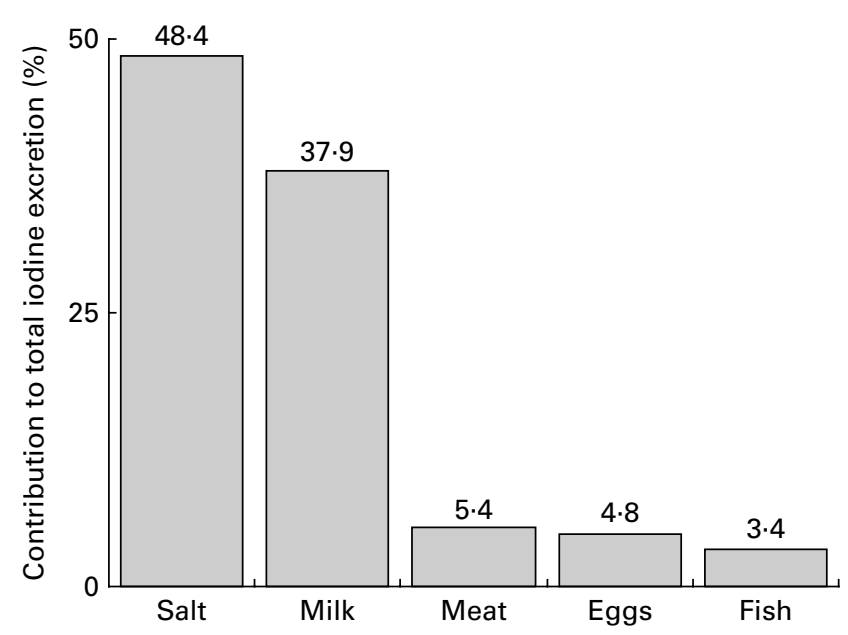

Fig. 2. Percentage contribution of the investigated food groups to estimated urinary iodine excretion, calculated by median daily dietary intakes $(\mathrm{g} / \mathrm{d})$ and respective regression coefficients $(\mu \mathrm{g} / \mathrm{g})$ of the mixed linear regression model (2004-9; Table 3)

limitation of our study is the elaborate design of the DONALD Study that results in a select population which is not representative with respect to socio-economic status ${ }^{(44)}$. Nevertheless, measured UIE rates in 2004-6 were in the same range as the results of the nationwide representative KiGGS Study in 2003-6 (KiGGS median urinary iodine concentration $(\mu \mathrm{g} / \mathrm{l})$ of boys: $127 \cdot 0$ ( $7-10$ years), $123 \cdot 2$ (11-13 years); girls: $115 \cdot 6$ $(7-10$ years $), \quad 104 \cdot 1 \quad(11-13 \text { years })^{(9,47)}$; DONALD $(6-12$ years) boys: $120 \cdot 1$, girls: $99 \cdot 2)$ and therefore underline the nationwide relevance of our results. The distinct advantage of the DONALD Study is the simultaneous collection of repeated 24-h urine samples and weighed dietary records. The combination of 24-h urinary iodine measurements with dietary data provides a sensitive monitoring instrument for the characterisation of iodine status, its most important dietary determinants, and the underlying changes and time trends.

In conclusion, the iodine status of German schoolchildren, only recently classified as almost adequate, apparently began to deteriorate from 2007. A decreased use of iodised salt in industrially produced foods may be one possible reason for the declining trend. Since it is known that in children in particular, even a mild iodine deficiency leads to an increased risk of developing mental impairment ${ }^{(10,12)}$, our data emphasise the need for promoting the use of iodised salt, especially in processed foods (currently, only about $26 \%$ of industrially used salt is iodised in Germany). Iodised salt added to processed foods has been shown to be a suitable vehicle for iodine fortification as it has emerged to be highly stable, especially in cereal products where the observed retention of iodine was $100 \%{ }^{(48)}$. The examination of the stability of iodised salt added to meat products revealed iodine losses of $7-25 \%$ after storage and cooking ${ }^{(49)}$. Against the background of the recommendations for reduction in salt intake as a public health measure worldwide, an increment of the iodine concentrations in salt should be considered. The present investigation can be seen as an initial health warning for the probable future development of iodine status in populations consuming relevant amounts of processed foods.

\section{Acknowledgements}

The present examination was supported in part by the Federal Ministry of Food, Agriculture and Consumer Protection (BMELV) through the Federal Agency for Agriculture and Food (BLE), grant no. 07HS002. The DONALD Study is funded by the Ministry of Science and Research of North Rhine Westphalia, Germany. The authors are very grateful to the staff of the Research Institute of Child Nutrition for carrying out the anthropometric measurements, and for collecting and coding the dietary records. In particular, the authors thank Monika Friedrich and Brigitte Nestler for expert laboratory assistance. None of the authors has any conflict of interest in regard to the present study. The contributions of the authors to this study are as follows: T. R. designed the research; S. A. J. and A. L. B. G. performed the statistical analysis; S. A. J. wrote the paper; S. A. J. and T. R. had primary responsibility for the final content. All authors made significant contributions to and approved the final manuscript.

The paper is dedicated to Professor Friedrich Manz, the former director of the Research Institute of Child Nutrition, on the occasion of his 70th birthday.

\section{References}

1. Zimmermann MB (2009) Iodine deficiency. Endocr Rev 30 , 376-408.

2. Mannar M (2004) Iodized salt for the elimination of iodine deficiency disorders. In Towards The Global Elimination of Brain Damage Due to Iodine Deficiency [B Hetzel, editor]. Oxford: Oxford University Press.

3. Andersson M, de Benoist B, Darnton-Hill I, et al. (2007) Iodine Deficiency in Europe: A Continuing Public Health Problem. Geneva: WHO Press.

4. Ristic-Medic D, Piskackova Z, Hooper L, et al. (2009) Methods of assessment of iodine status in humans: a systematic review. Am J Clin Nutr 89, 2052S-2069S.

5. Vejbjerg P, Knudsen N, Perrild H, et al. (2009) Estimation of iodine intake from various urinary iodine measurements in population studies. Thyroid 19, 1281-1286.

6. Remer T \& Neubert A (1998) A never-ending story of an insufficient iodine status without mandatory iodization of foods? A German experience. J Clin Endocrinol Metab 83, 3755-3756.

7. Scriba P, Heseker H \& Fischer A (2007) Iodine deficiency and supplementation in Germany. Success of public information and prevention as exemplified by iodized salt (article in German). Präv Gesundheitsf 2, 143-148.

8. Remer T, Fonteyn N, Alexy U, et al. (2006) Longitudinal examination of 24-h urinary iodine excretion in schoolchildren as a sensitive, hydration status-independent research tool for studying iodine status. Am J Clin Nutr 83, 639-646.

9. Thamm M, Ellert U, Thierfelder W, et al. (2007) Iodine intake in Germany. Results of iodine monitoring in the German Health Interview and Examination Survey for Children and Adolescents (KiGGS) (article in German). Bundesgesundbeitsblatt Gesundheitsforschung Gesundheitsschutz $\mathbf{5 0}$ 744-749.

10. Gordon RC, Rose MC, Skeaff SA, et al. (2009) Iodine supplementation improves cognition in mildly iodine-deficient children. Am J Clin Nutr 90, 1264-1271.

11. Zimmermann MB, Connolly K, Bozo M, et al. (2006) Iodine supplementation improves cognition in iodine-deficient 
schoolchildren in Albania: a randomized, controlled, doubleblind study. Am J Clin Nutr 83, 108-114.

12. Santiago-Fernandez P, Torres-Barahona R, Muela-Martinez JA, et al. (2004) Intelligence quotient and iodine intake: a cross-sectional study in children. $J$ Clin Endocrinol Metab 89, 3851-3857.

13. Klaus D, Hoyer J \& Middeke M (2010) Salt restriction for the prevention of cardiovascular disease. Dtsch Arztebl Int 107, 457-462.

14. High Level Group on Diet Physical Activity and Health (2009) National Salt Initiatives implementing the EU Framework for salt reduction initiatives. http://ec.europa.eu/health/archive/ ph_determinants/life_style/nutrition/documents/national_salt_ en.pdf (accessed 15 August 2011).

15. World Health Organisation (2010) Creating an Enabling Environment for Population-Based Salt-reduction Strategies: Report of a Joint Technical Meeting Held by WHO and the Food Standards Agency, United Kingdom, July 2010. London: WHO and Food Standards Agency.

16. World Health Organisation (2007) Salt as a Vebicle for Fortification. Report of a WHO Expert Consultation. Luxembourg: WHO.

17. Tayie FA \& Jourdan K (2010) Hypertension, dietary salt restriction, and iodine deficiency among adults. $A m \mathrm{~J}$ Hypertens 23, 1095-1102.

18. Arbeitskreis Jodmangel (2008) Entwicklung der Marktanteile von jodiertem Speise-und Pökelsalz am gesamten Speisesalzabsatz in Großgebinden in Deutschland (Development of the market shares of iodized pickling salt and table salt in the total sales in large containers in Germany). http:// jodmangel.de/presseinfos/bilder/grossgebinde07.jpg (accessed 15 August 2011).

19. Remer T, Neubert A \& Maser-Gluth C (2002) Anthropometrybased reference values for 24-h urinary creatinine excretion during growth and their use in endocrine and nutritional research. Am J Clin Nutr 75, 561-569.

20. Sichert-Hellert W, Kersting M, Chahda C, et al. (2007) German food composition database for dietary evaluations in children and adolescents. J Food Comp Anal 20, 63-70.

21. Lorenz-Wawschinek O, Tiran B, Eber O, et al. (1994) Photometric determination of iodine in urine. Exp Clin Endocrinol 102, 357-358.

22. Lohman T, Roche A \& Martorell R (1988) Anthropometric Standardization Reference Manual. Champaign, IL: Human Kinetics.

23. Du Bois D \& Du Bois EF (1916) A formula to estimate the approximate surface area if height and weight be known. Arch Int Med 17, 863-871.

24. Kromeyer-Hauschild K, Wabitsch M, Kunze D, et al. (2001) Percentiles of body mass index in children and adolescents evaluated from different regional German studies (article in German). Monatsschr Kinderbeilkd 149, 807-818.

25. Verbeke G \& Molenberghs G (2000) PORC MIXED versus PROC GLM. In Linear Mixed Models for Longitudinal Data, pp. 119-120 [G Verbeke and G Molenberghs, editors]. New York, NY: Springer.

26. Johner SA, Shi L \& Remer T (2010) Higher urine volume results in additional renal iodine loss. Thyroid 20, 1391-1397.

27. Barr DB, Wilder LC, Caudill SP, et al. (2005) Urinary creatinine concentrations in the U.S. population: implications for urinary biologic monitoring measurements. Environ Health Perspect 113, 192-200.

28. Food and Nutrition Board \& Institute of Medicine (2001) Dietary Reference Intakes for Vitamin A, Vitamin K, Arsenic, Boron, Chromium, Copper, Iodine, Iron, Manganese,
Molybdenum, Nickel, Silicon, Vanadium, and Zinc. Washington, DC: National Academy Press.

29. Meng W \& Scriba P (2002) Iodine supply in Germany - problems and necessary measures: update 2002 (article in German). Deutsches Aerzteblatt 99, A2560-A2564.

30. Rauh M, Verwied-Jorky S, Gröschl M, et al. (2003) Current state of iodine supply in primary school children in Erlangen (article in German). Monatsschr Kinderheilkd 151, 957-961.

31. Gärtner R, Manz F \& Grossklaus R (2001) Representative data of iodine intake and urinary excretion in Germany. Exp Clin Endocrinol Diabetes 109, 2-7.

32. Riggs DS (1952) Quantitative aspects of iodine metabolism in man. Pharmacol Rev 4, 284-370.

33. Food and Nutrition Board \& Institute of Medicine (2000) Dietary Reference Intakes: Applications in Dietary Assessment. Washington, DC: National Academic Press.

34. Gärtner R (2009) Jodversorgung in Deutschland - Was ist noch zu tun? http://www.jodmangel.de/newsletter/newsletter_ 2009.pdf (accessed 15 August 2011)

35. Verordnung über diätetische Lebensmittel (Diätverordnung), in the version of publication from 28.04.2005. In (Bundesgesetzblatt I, 1161), last change 01.10.2010 (Bundesgesetzblatt I, 1306).

36. FAO Fisheries and Aquaculture Department (2009) The State of World Fisheries and Aquaculture 2008. Rome: Food and Agriculture Organization of the United Nations.

37. Karl H \& Meyer C (2002) Investigations in respect to the quality of gilthead seabream on the German market (article in German). Inf Fischwirtsch Fischereiforsch 49, 20-24.

38. Wenlock RW, Buss DH, Moxon RE, et al. (1982) Trace nutrients. 4. Iodine in British food. Br J Nutr 47, 381-390.

39. Hampel R, Kairies J \& Below H (2009) Beverage iodine levels in Germany. Eur Food Res Technol 229, 705-708.

40. Anonymous (2007) Bio ist am Besten (article in German). Test 11, 16-22.

41. Dyer A, Elliott P, Chee D, et al. (1997) Urinary biochemical markers of dietary intake in the INTERSALT study. $A m J$ Clin Nutr 65, 1246S-1253S.

42. Vandevijvere S, De Keyzer W, Chapelle JP, et al. (2010) Estimate of total salt intake in two regions of Belgium through analysis of sodium in 24-h urine samples. Eur $J$ Clin Nutr 64, 1260-1265.

43. Food and Nutrition Board \& Institute of Medicine (2004) Dietary Reference Intakes for Water, Potassium, Sodium, Chloride and Sulfate. Washington, DC: National Academic Press.

44. Kroke A, Manz F, Kersting M, et al. (2004) The DONALD Study. History, current status and future perspectives. Eur J Nutr 43, 45-54.

45. Cutler JA \& Roccella EJ (2006) Salt reduction for preventing hypertension and cardiovascular disease: a population approach should include children. Hypertension 48, 818-819.

46. Ebner A \& Manz F (2002) Sex difference of urinary osmolality in German children. Am J Nephrol 22, 352-355.

47. Thamm M, Karaolis-Dankert N \& Kroke A, et al. (2007) Bericht zur Jodversorgung deutscher Kinder und Jugendlicher auf Basis der Daten des 'Jod-Moduls' im Rahmen der KiGGS Studie (Report on the iodine status of German children and adolescents based on data from the 'iodine-module' in the context of the KiGGS study). http://www.bmelv.de/SharedDocs/ Downloads/Ernaehrung/JodMonitoring.html (accessed 15 August 2011)

48. Thomson BM (2009) Stability of added iodine in processed cereal foods. Food Addit Contam Part A Chem Anal Control Expo Risk Assess 26, 25-31.

49. Wirth F \& Kühne D (1991) Manufacture of iodised meat products. Fleischwirtschaft 71, 1377-1384. 